\title{
Влияние рН среды на протекание процессов адсорбции ионов меди, никеля и цинка иголками лиственницы сибирской (Larix Sibirica)
}

\author{
(c) 2020 Галимова Р.3. ${ }^{1}$, Шайхиев И.Г. ${ }^{1}$, Камалова Н.А. ${ }^{1}$, Свергузова С.В. ${ }^{2}$ \\ ${ }^{I}$ ФБОУ ВО «Казанский национальный исследовательский технологический университет, Казань \\ ${ }^{2}$ ФББОУ ВО «Белгородский государственный технологический университет им. В.Г. Шухова», \\ Белгород
}

Поступила в редакцию 12.02.2020 г.

DOI: $10.17308 /$ sorpchrom.2020.20/2877

Одними из наиболее токсичных поллютантов, попадающих в водоемы со сточными водами гальванического производства являются ионы тяжелых металлов. В последние годы широко исследуются сорбционные свойства дешевых и доступных целлюлозосодержащих сорбционных материалов на основе отходов растительного сырья. В частности, к таковым относятся иголки лиственницы сибирской Larix Sibirica.

Не смотря на большое количество работ, направленных на исследование механизмов процессов сорбции ионов тяжелых металлов целлюлозосодержащими материалами, а также влияния рН среды на механизм протекания процессов, в настоящее время, нет единого мнения относительно механизмов процессов сорбции ионов тяжелых металлов целлюлозосодержащими материалами и выбора модели сорбции для описания этих процессов.

На основании сказанного, в статических условиях на модельных растворах ионов тяжелых металлов объемом $100 \mathrm{~cm}^{3}$ с содержанием ионов от 10 до 1500 мг/дм³ и при дозировки сорбционного материала 1 г и при рН среды 2, 4 и 6 изучены сорбционные свойства иголок лиственницы сибирской по отношению к ионам меди, никеля и цинка. Максимальные значения сорбционной ёмкости иголок лиственницы по ионам $\mathrm{Cu}^{2+}, \mathrm{Ni}^{2+}$ и $\mathrm{Zn}^{2+}$ составляют соответственно 48.8, 17.4 и 36.0 мг/г. Процесс сорбции ионов меди $\left(\mathrm{Cu}^{2+}\right)$ наиболее полно протекает при $\mathrm{pH}=4$, ионов никеля $\left(\mathrm{Ni}^{2+}\right)-$ при $\mathrm{pH}=6$, а ионов цинка $\left(\mathrm{Zn}^{2+}\right)$ - одинаково хорошо при $\mathrm{pH}=4$ и $\mathrm{pH}=6$. Обработкой полученных изотерм адсорбции в рамках мономолекулярных моделей сорбции: Ленгмюра, Фрейндлиха, Дубинина-Радушкевича, Темкина обнаружено, что в слабокислой среде $(\mathrm{pH}=6)$ наблюдается преимущественно адсорбция ионов тяжелых металлов в порах, а в кислой среде $(\mathrm{pH=2-4)}$ - на поверхности материала путём взаимодействия ионов тяжелых металлов с активными центрами, равномерно расположенными на поверхности иголок. Используя константы уравнений Ленгмюра и Дубинина-Радушкевича рассчитаны термодинамические параметры процессов: энергии сорбции и энергии Гиббса, значения которых указывают на протекание самопроизвольной физической адсорбции.

Ключевые слова: ионы тяжелых металлов, иголки лиственницы сибирской, адсорбция, модели адсорбции, термодинамика

\section{Введение}

Даже при совершенствовании старых и создание новых, технологий, к числу наиболее вредных производств относится гальваническое [1-3]. Оно отличается большим потреблением воды высокого качества и сбросом большого количества отходов [1-5]. В гальванических сточных водах содержится целый ряд чрезвычайно токсичных примесей, но наиболее опасны для окружающей среды ионы тяжелых металлов - кадмия, меди, цинка, хрома, никеля, свинца [7-10]. 
Существует ряд работ, направленных на исследование сорбционных свойств по отношению к ионам тяжелых металлов целлюлозосодержащих материалов [1115]. С целью определения механизмов протекания процессов сорбции целлюлозными материалами полученные изотермы обрабатываются рядом моделей сорбции, среди них наиболее распространенными являются модели: Ленгмюра, Фрейндлиха, Дубинина-Радушкевича, Темкина и др. [16-21]. Однако, в настоящее время, нет единого мнения относительно механизмов процессов сорбции ионов тяжелых металлов целлюлозосодержащими материалами и выбора модели сорбции для описания этого процесса [22-24].

Среди возможных механизмов сорбции ионов тяжелых металлов целлюлозными материалами выделяют: ионный обмен на группах $-\mathrm{COOH}$, ионный обмен и комплексообразование за счет взаимодействия с группами -OH, а также комплексообразование с участием всех атомов кислорода элементарного звена целлюлозы [2528]. Таким образом, важным моментом в исследовании механизмов процессов сорбции ионов тяжелых металлов целлюлозными материалами является исследование процессов в области рН 1-7, при которых наблюдается максимальное количество карбоксильных групп в протонированной форме [29].

В связи с вышесказанным и в продолжение работам [30-34] сформулирована цель работы: изучение влияния $\mathrm{pH}$ на протекание процессов сорбции ионов меди, никеля и цинка из водных сред иголками лиственницы сибирской Larix Sibirica.

\section{Экспериментальная часть}

Процессы сорбции ионов меди, никеля и цинка иголками лиственницы сибирской исследовались в статических условиях на модельных растворах ионов тяжелых металлов объемом $100 \mathrm{~cm}^{3}$ с содержанием ионов от 10 до 1500 мг/дм ${ }^{3}$ и при дозировки сорбционного материала 1 г. Колбы с гетерогенными системами плотно закрывались пробками и перемешивались 3 часа на магнитных мешалках со скоростью 1000 оборотов в минуту и при температуре среды $20^{\circ} \mathrm{C}$. Раствор отфильтровывался через бумажный фильтр, а в фильтратах определялись концентрации ионов $\mathrm{Cu}^{2+}, \mathrm{Ni}^{2+}$ и $\mathrm{Zn}^{2+}$. $\mathrm{pH}$ растворов доводили до значений 2,4 и 6 добавлением в систему необходимого количества соляной кислоты.

По полученным значениям начальных и конечных концентраций ионов в растворе определялась сорбционная ёмкость материала по формуле 1:

$$
\mathrm{A}=\left(\left(\mathrm{C}_{\mathrm{S}}-\mathrm{C}_{\mathrm{e}}\right) \cdot 100\right) /(1 \cdot 1000)
$$

где $C_{s}$ - исходная концентрация ионов металла, мг/дм ${ }^{3} ; C_{e}-$ конечная концентрация ионов металла, мг/дм³ $; 100$ - объем раствора, см $^{3} ; 1$ - вес СМ, г; 1000 - переход от $\mathrm{cm}^{3} \kappa д \mathrm{M}^{3}$.

По полученным значениям сорбционной емкости (А) иголок лиственницы сибирской при различных $\mathrm{pH}$ растворов и равновесных концентрациях ионов $\mathrm{Cu}(\mathrm{II})$, $\mathrm{Ni}(\mathrm{II})$ и $\mathrm{Zn}(\mathrm{II})$ строились изотермы адсорбции.

\section{Обсуждение результатов}

Полученные изотермы адсорбции приведены на рисунках 1-4. Изотермы адсорбции ионов меди, никеля и цинка иголками лиственницы сибирской при $\mathrm{pH}=6$ можно отнести к типичным Ленгмюровским изотермам (так называемым L-типу или I типу изотерм), которые описывают мономолекулярную адсорбцию ионов на поверхности иголок лиственницы сибирской. Общеизвестно, что данный тип изотерм характерен для микропористых твёрдых тел с относительно малой долей внешней 
поверхности. Максимальная сорбционная емкость иголок лиственницы по ионам меди, никеля и цинка соответственно равна $\mathrm{A}=48.8,17.4$ и 36.0 мг/г $(0.77,0.30$ и 0.56 ммоль/г).

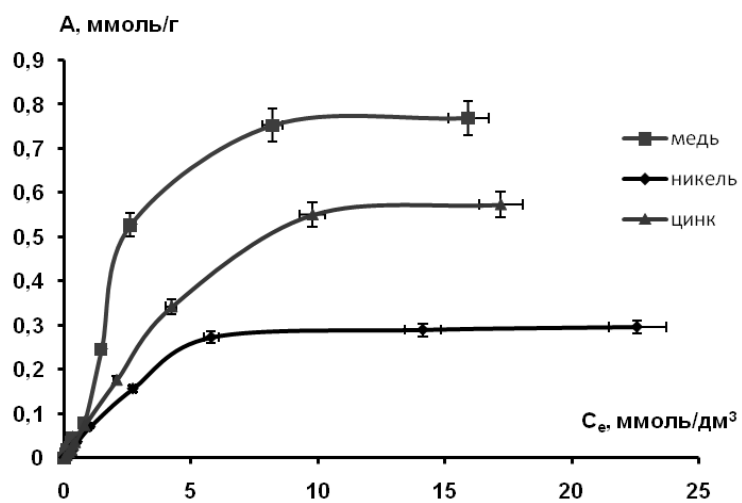

Рис. 1 Изотермы адсорбции ионов $\mathrm{Cu}^{2+}$, $\mathrm{Ni}^{2+}$ и $\mathrm{Zn}^{2+}$ иголками лиственницы сибирской при $\mathrm{pH}=6$

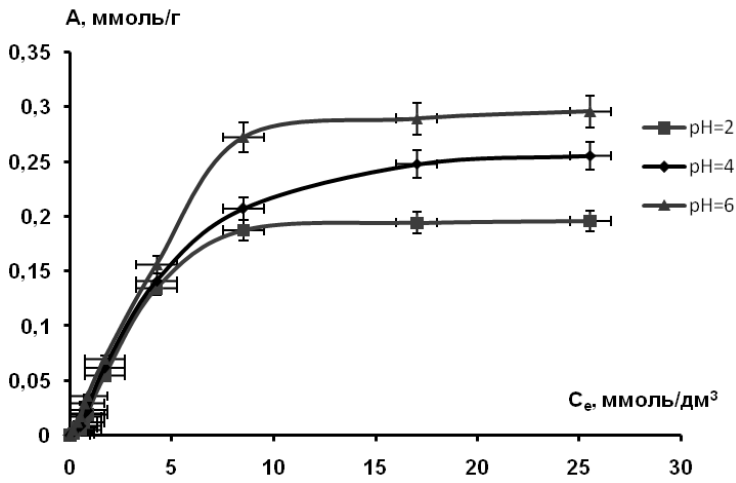

Рис. 3 Изотермы адсорбции ионов $\mathrm{Ni}^{2+}$ при $\mathrm{pH}=2, \mathrm{pH}=4$ и $\mathrm{pH}=6$

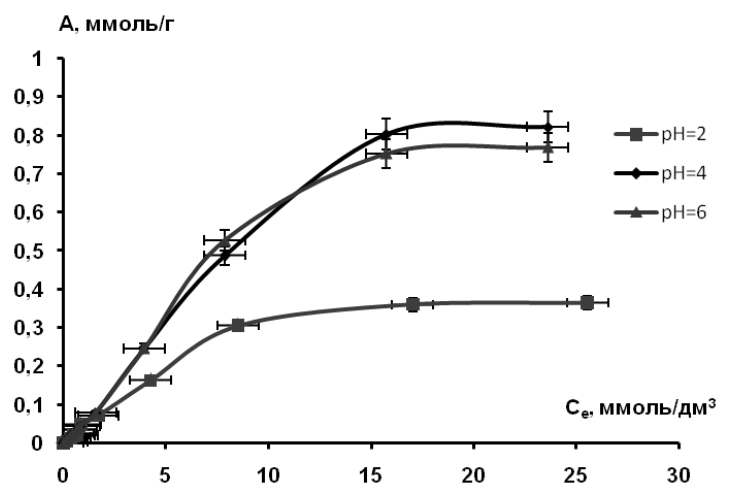

Рис. 2 Изотермы адсорбции ионов $\mathrm{Cu}^{2+}$ при $\mathrm{pH}=2, \mathrm{pH}=4$ и $\mathrm{pH}=6$

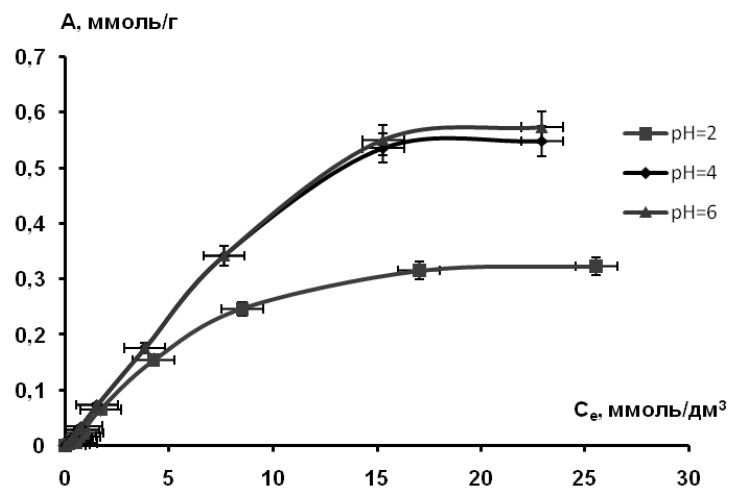

Рис. 4 Изотермы адсорбции ионов $\mathrm{Zn}^{2+}$ при $\mathrm{pH}=2, \mathrm{pH}=4$ и $\mathrm{pH}=6$

Влияние $\mathrm{pH}$ среды на протекание процессов сорбции ионов меди, никеля и цинка представлены на рисунках 2-4 соответственно. Из рисунков 2-4 видно, что рН среды влияет на протекание процессов сорбции ионов тяжелых металлов иголками лиственницы сибирской (Larix Sibirica). Процесс сорбции ионов меди $\left(\mathrm{Cu}^{2+}\right)$ наиболее полно протекает при $\mathrm{pH}=4$, ионов никеля $\left(\mathrm{Ni}^{2+}\right)-$ при $\mathrm{pH}=6$, а ионов цинка $\left(\mathrm{Zn}^{2+}\right)$ - одинаково хорошо при $\mathrm{pH}=4$ и $\mathrm{pH}=6$. Данное обстоятельство может свидетельствовать о том, что процессы сорбции ионов тяжелых металлов зависят от количества карбоксильных групп на поверхности целлюлозного материала в протонированной форме, при этом с увеличением количества карбоксильных групп в протонированной форме сорбционная ёмкость по ионам возрастает. Дополнительным подтверждением могут служить данные, полученные путём обработки полученных изотерм адсорбции в рамках мономолекулярных моделей сорбции: Ленгмюра, Фрейндлиха, Дубинина-Радушкевича, Темкина (табл.1).

Из таблицы 1 видно, что при переходе рН среды в кислую область (от 4 до 2 для ионов меди и цинка, от 6 до 4 для ионов никеля) наблюдается изменение модели, описывающих механизм процессов сорбции с модели Дубинина-Радушкевича на модель Ленгмюра, то есть в слабокислой среде $(\mathrm{pH}=6)$ наблюдается преимущественно адсорбция ионов тяжелых металлов в порах целлюлозосодержащего материала, а в кислой среде $(\mathrm{pH}=2-4)$ - на поверхности материала путём взаимодействия ионов 
тяжелых металлов с активными центрами, равномерно расположенными на поверхности иголок лиственницы сибирской [35].

Таблица 1. Результаты обработки изотерм адсорбции ионов меди, никеля и цинка иголками лиственницы сибирской в рамках мономолекулярных моделей сорбции

\begin{tabular}{|c|c|c|c|c|c|}
\hline Ион & $\mathrm{pH}$ & $\mathrm{A}_{\infty}$, ммоль/Г & Модель & Уравнение & $\mathrm{R}^{2}$ \\
\hline \multirow{3}{*}{$\mathrm{Cu}^{2+}$} & 2 & $0.36 \pm 0.02$ & Дубинина-Радушкевича & $\mathrm{y}=-1.325 \mathrm{x}-1.081$ & 0.955 \\
\cline { 2 - 6 } & 4 & $0.82 \pm 0.04$ & Ленгмюра & $\mathrm{y}=1.321 \mathrm{x}+5.272$ & 0.990 \\
\cline { 2 - 6 } & 6 & $0.77 \pm 0.04$ & Ленгмюра & $\mathrm{y}=1.205 \mathrm{x}+5.906$ & 0.990 \\
\hline \multirow{3}{*}{$\mathrm{Ni}^{2+}$} & 2 & $0.20 \pm 0.01$ & Дубинина-Радушкевича & $\mathrm{y}=-1.028 \mathrm{x}-0.475$ & 0.969 \\
\cline { 2 - 6 } & 4 & $0.25 \pm 0.01$ & Дубинина-Радушкевича & $\mathrm{y}=-1.015 \mathrm{x}-0.417$ & 0.970 \\
\cline { 2 - 6 } & 6 & $0.30 \pm 0.02$ & Ленгмюра & $\mathrm{y}=2.257 \mathrm{x}+8.540$ & 0.971 \\
\hline \multirow{3}{*}{$\mathrm{Zn}^{2+}$} & 2 & $0.32 \pm 0.02$ & Дубинина-Радушкевича & $\mathrm{y}=-1.007 \mathrm{x}-0.395$ & 0.967 \\
\cline { 2 - 6 } & 4 & $0.55 \pm 0.03$ & Ленгмюра & $\mathrm{y}=1.308 \mathrm{x}+5.182$ & 0.988 \\
\cline { 2 - 6 } & 6 & $0.56 \pm 0.03$ & Ленгмюра & $\mathrm{y}=1.274 \mathrm{x}+5.423$ & 0.991 \\
\hline
\end{tabular}

На следующем этапе исследования, с целью выявления природы взаимодействия ионов тяжелых металлов с активными центрами иголок лиственницы, были рассчитаны термодинамические константы процессов сорбции: энергии Гиббса $(\Delta \mathrm{G})$ по формуле 2 с использованием констант уравнения Ленгмюра $\left(\mathrm{K}_{\mathrm{L}}\right)$ и энергии сорбции (Е), определенной по уравнению Дубинина-Радушкевича (табл.2).

$$
\Delta \mathrm{G}^{\mathrm{o}}=-\mathrm{R} \cdot \mathrm{T} \cdot \ln \mathrm{K}_{\mathrm{L}}
$$

где $\Delta \mathrm{G}^{\mathrm{o}}$ - энергия Гиббса (Дж/моль), $\mathrm{R}$ - универсальная газовая постоянная, $\mathrm{K}_{\mathrm{L}}$ - константа Ленгмюра.

Таблица 2. Термодинамические константы процессов адсорбции ионов меди, никеля и цинка иголками лиственницы сибирской Larix Sibirica

\begin{tabular}{|c|c|c|c|}
\hline \multirow{2}{*}{ Ион } & $\mathrm{pH}$ & Е, кДж/моль & $\Delta \mathrm{G}$, кДж/моль \\
\hline \multirow{3}{*}{$\mathrm{Cu}^{2+}$} & 2 & $2.116 \pm 0.001$ & $-3.115 \pm 0.001$ \\
\cline { 2 - 4 } & 4 & $2.204 \pm 0.001$ & $-3.371 \pm 0.001$ \\
\cline { 2 - 4 } & 6 & $2.588 \pm 0.001$ & $-3.872 \pm 0.001$ \\
\hline \multirow{3}{*}{$\mathrm{Ni}^{2+}$} & 2 & $3.534 \pm 0.001$ & $-3.104 \pm 0.001$ \\
\cline { 2 - 4 } & 4 & $3.772 \pm 0.001$ & $-3.208 \pm 0.001$ \\
\cline { 2 - 4 } & 6 & $3.956 \pm 0.001$ & $-3.317 \pm 0.001$ \\
\hline \multirow{3}{*}{$\mathrm{Zn}^{2+}$} & 2 & $3.876 \pm 0.001$ & $-3.354 \pm 0.001$ \\
\cline { 2 - 4 } & 4 & $3.912 \pm 0.001$ & $-3.028 \pm 0.001$ \\
\cline { 2 - 4 }
\end{tabular}

Значения энергий сорбции (Е) в пределах от 2 до 4 кДж/моль и отрицательные значения $\Delta \mathrm{G}$ в пределах от -4 до -3 кДж/моль свидетельствуют о самопроизвольном протекании физической адсорбции во всех случаях [36].

\section{Заключение}

На модельных системах - растворах ионов меди (II), никеля (II) и цинка (II) с различными начальными концентрациями ионов в растворе в статических условиях изучены сорбционные свойства иголок лиственницы сибирской. Установлено, что экспериментальные максимальные сорбционные ёмкости иголок лиственницы сибирской по отношению к ионам $\mathrm{Cu}^{2+}, \mathrm{Ni}^{2+}$ и $\mathrm{Zn}^{2+}$ составляют 48.8, 17.4 и 36.0 мг/Г соответственно. Изучено влияние $\mathrm{pH}$ на протекание процессов сорбции ионов тяже- 
лых металлов иголками лиственницы. Выявлено, что наиболее полно протекает процесс адсорбции при значениях $\mathrm{pH}$ в области 4-6. Изучены механизмы процессов сорбции ионов меди, никеля и цинка иголками лиственницы сибирской при значениях рН среды 2, 4 и 6 путем обработки полученных изотерм адсорбции в рамках моделей сорбции Ленгмюра, Фрейндлиха, Дубинина-Радушкевича, Темкина. Определены уравнения процессов и их коэффициенты аппроксимации. Выявлено, что в слабокислой среде ( $\mathrm{pH}=6)$ наблюдается преимущественно адсорбция ионов тяжелых металлов в порах целлюлозосодержащего материала, а в кислой среде ( $\mathrm{pH}=2-4)$ - на поверхности материала путём взаимодействия ионов тяжелых металлов с активными центрами, равномерно расположенными на поверхности иголок лиственницы сибирской. Рассчитанные значения термодинамических величин процессов: энергии сорбции и энергии Гиббса указывают на самопроизвольное протекание физической адсорбции во всех случаях.

\section{Список литературы}

1. Филатова Е.Г., Пожидаев Ю.Н., Помазкина О.И. // Физикохимия поверхности и защита материалов. 2019. Т. 55. № 5. С. 507512.

2. Летенкова И.В. // Вестник СанктПетербургского государственного университета технологии и дизайна. Серия 1: Естественные и технические науки. 2019. № 2. C. $79-82$.

3. Линников О.Д., Родина И.В., Бакланова И.В., Сунцов А.Ю. // Сорбиионные и хроматографические проиессы. 2018. Т. 18. № 4. C. 554-562.

4. Абрамова А.Ю., Юрченко В.В. // Химия. Экология. Урбанистика. 2018. Т. 1. С. 185188.

5. Линников О.Д., Родина И.В., Сунцов А.Ю. // Сорбиионные и хроматографические nроиессы. 2017. Т. 17. № 5. С. 725-732.

6. Филатова Е.Г., Помазкина О.И., Пожидаев Ю.Н. // Физикохимия поверхности и защита материалов. 2017. Т. 53. № 6. С. 596-601.

7. Юрьева А.В., Бутова Т.С. // Динамика систем, механизмов и машин. 2014. № 3. С. 318-320.

8. Максатова А.М., Везенцев А.И., Михайлюкова М.О., Калашникова Л.А. // Вестник современных исследований. 2017. № 7-1 (10). C. 162-169.

9. Свиридов А.В., Юрченко В.В., Свиридов В.В., Ганебных Е.В. // Сорбционные и хроматографические прочессы. 2016. Т. 16. № 1. C. $78-86$.

10.Линников О.Д., Родина И.В., Тютюнник А.П., Еселевич Д.А. и др. // Вода: химия и экология. 2016. № 7 (97). С. 72-80.

11.Харлямов Д.А., Насыров И.А., Маврин Г.В., Шайхиев И.Г. // Вестник Технологического университета. 2015. Т. 18. № 12. С. 204-206.

12.Милютина А.Д., Колесников В.А. // Успехи в химии и химической технологии. 2015. T. 29. № 1 (160). С. 43-45.

13.Цветкова А.Д., Акаев О.П. // Вестник Костромского государственного университета им. Н.А. Некрасова. 2011. Т. 17. № 2. C. 27-30.

14.Ахрименко В.Е., Ахрименко 3.М., Сидорова И.И., Потеряев А.В. // Наука Кубани. 2009. № 4. С. 20-23.

15.Пимнева Л.А., Лебедева А.А. // Международный журнал экспериментального образования. 2016. № 9-1. С. 69-70.

16.Милютина А.Д., Колесников В.А., Колесников А.В. // Успехи в химии и химической технологии. 2016. Т. 30. № 1 (170). С. 42-43.

17.Denisova T.R., Sokolov M.P., Galimova R.Z., Shaikhiev I.G. // International Journal of Green Pharmacy. 2017. Vol. 11. No 4. pp. S872-S876.

18.Denisova T.R., Mavrin G.V., Galimova R.Z., Shaikhiev I.G. // Research Journal of Pharmaceutical, Biological and Chemical Sciences. 2016. Vol. 7. No 5. pp. 1765-1771.

19.Мифтахова Ф.Р., Нгуен Т.К.Т., Галимова Р.3., Шайхиев И.Г. // Вестник Технологического университета. 2019. Vol. 22. No 2. pp. 37-43.

20.Мифтахова Ф.Р., Нгуен Т.К.Т., Галимова Р.З., Шайхиев И.Г. и др. // Сорбиионные и хроматографические проиессы. 2019. Т. 19. № 5. C. 588-595.

Галимова и др. / Сорбционные и хроматографические процессы. 2020. Т. 20. № 3. С. 400-407 
21.Галимова Р.З., Нгуен Т.К.Т., Шайхиев И.Г., Свергузова С.В. // Chemical Bulletin. 2019. T. 2. № 4. С. 12-23.

22.Угрозов В.В., Филиппов А.Н., Сидоренко Ю.И. // Журнал физической химии. 2007. T. 81. № 3. C. 458-461.

23.Nguyen K.T.T., Galimova R.Z., Shaikhiev I.G., Denisova T.R., Sippel I.Y. // International Journal of Green Pharmacy. 2018. Vol. 12. No 4. pp. S895-S899.

24.Ким Тхоа Н.Т., Сидоровнина О.О., Замалиева Л.А., Мифтахова Ф.Р. и др. // Вестник Технологического университета. 2017. T. 20. № 18. C. 159-162.

25.Дагаева Е.В., Валинурова Э.Р. // Вестник Башкирского университета. 2019. Т. 24. № 1. C. 71-75.

26.Никифорова Т.Е., Козлов В.А., Родионова М.В., Модина Е.А. // Известия высших учебных заведений. Серия: Химия и химическая технология. 2009. Т. 52. № 3. С. 27-31.

27.Багровская Н.А., Никифорова Т.Е., Козлов В.А., Лилин С.А. // Химия в интересах устойчивого развития. 2006. Т. 14. № 1. С. 1-7.

28.Никифорова Т.Е., Багровская Н.А., Козлов В.А., Лилин С.А. // Химия растительного сырья. 2009. № 1. С. 5-14.

29. Bagrovskaya N.A., Nikiforova T.E., Kozlov V.A. // Russian Journal of Physical Chemistry A. 1999. Vol. 73. No 8. pp. 1305-1309.

30.Камалова Н.А., Шайхиев И.Г., Садыкова С.В., Галимова Р.3. // «Инновационные подходы в решении современных проблем рационального использования природных ре- сурсов и охраны окружающей среды», сборник докладов Международной научнотехнической конференции. 2019. С. 196-201.

31.Denisova T.R., Kharlyamov D.A., Galimova R.Z., Shaikhiev I.G. et al. // International Journal of Engineering and Technology(UAE). 2018. Vol. 7. No 4.7. pp. 219-222.

32.Камалова Н.А., Галимова Р.3., Шайхиев И.Г., Садыкова С.В. и др. // Вестник Технологического университета. 2017. Т. 20. № 19. C. 121-124.

33.Камалова Н.А., Шайхиев И.Г., Садыкова С.В. // «Актуальные вопросы охраны окружающей среды», сборник докладов Всероссийской научно-технической конференции. 2018. C. 114-118.

34.Камалова Н.А., Шайхиев И.Г., Садыкова С.В. // «Инновационные пути решения актуальных проблем природопользования и защиты окружающей среды», сборник докладов Международной научно-технической конференции. 2018. С. 113-120.

35.Галимова Р.3., Шайхиев И.Г. Очистка фенолсодержащих сточных вод нативными и модифицированными адсорбционными материалами на основе отходов сельскохозяйственного и промышленного производства. Белгород-Казань. 2018. 96 с.

36.Галимова Р.3., Шайхиев И.Г. // «Инновационные подходы в решении современных проблем рационального использования природных ресурсов и охраны окружающей среды», сборник докладов Международной научно-технической конференции. 2019. С. 160-166.

\title{
The influence of the $\mathrm{pH}$ of the medium on the process of adsorption of copper, nickel, and zinc ions by Siberian larch needles (Larix Sibirica)
}

\author{
(C) 2020 Galimova R.Z. ${ }^{1}$, Shaikhiev I.G. ${ }^{1}$, Kamalova N.A. ${ }^{1}$, Sverguzova S.V. ${ }^{2}$ \\ ${ }^{1}$ Kazan National Research Technical Universitynamed after A. N. Tupolev, Kazan \\ ${ }^{2}$ Belgorod State Technological University named after V. G. Shukhov, Belgorod
}

Heavy metal ions are one of the most toxic pollutants found in the water reservoirs as a result of waste water disposal in electroplating industry. Recently, there has been a lot of research into the sorption properties of inexpensive and available sorption materials containing cellulose produced from plant waste. One such material is the Siberian larch needle (Larix Sibirica).

Although there are a great number of works dedicated to the study of sorption processes of heavy metals by materials containing cellulose and the effect of the $\mathrm{pH}$ of the medium on the course of the process, there is still no agreement on the mechanisms of sorption processes of heavy metals by materials containing cellulose and the adsorption model to describe these processes. 
Therefore, the sorption properties of Siberian larch needles with regard to copper, nickel, and zinc ions were studied in statistic conditions with simulated solutions of heavy metal ions with a volume of 100 $\mathrm{cm}^{3}$ and ion content between 10 and $1,500 \mathrm{mg} / \mathrm{dm}^{3}$, the dose of the sorption material of $1 \mathrm{~g}$, and the $\mathrm{pH}$ of the medium of 2, 4, and 6. The maximum values of larch needle sorption capacity for $\mathrm{Cu}^{2+}, \mathrm{Ni}^{2+}$, and $\mathrm{Zn}^{2+}$ ions are $48.8,17.4$ and $36.0 \mathrm{mg} / \mathrm{g}$ respectively. The sorption process for copper ions $\left(\mathrm{Cu}^{2+}\right)$ is the most evident at the $\mathrm{pH}=4$, for nickel ions $\left(\mathrm{Ni}^{2+}\right)$ at the $\mathrm{pH}=6$, and for zinc ions $\left(\mathrm{Zn}^{2+}\right)$ sorption is equally good at $\mathrm{pH}=4$ and $\mathrm{pH}=6$. The processing of the obtained isotherms using monomolecular adsorption models (Langmuir, Freundlich, Dubinin-Radushkevich, and Temkin equations) revealed that in weak acid media ( $\mathrm{pH}=6)$ heavy metal ions are mainly adsorbed in pores, while in acidic media $(\mathrm{pH=2-4)}$ they are adsorbed on the surface of the material as a result of interaction of heavy metals with active centres uniformly distributed over the needle surface. Langmuir and Dubinin-Radushkevich equation constants were used to calculate the thermodynamic parameters of the processes. The values for the energy of adsorption and Gibbs free energy indicate the presence of spontaneous physical adsorption.

Keywords: heavy metal ions, Siberian larch needles, adsorption, adsorption models, thermodynamics

\section{References}

1. Filatova E.G., Pozhidaev Ju.N., Pomazkina O.I., Fizikohimija poverhnosti $i$ zashhita materialov, 2019, Vol. 55, No 5, pp. 507-512.

2. Letenkova I.V., Vestnik SanktPeterburgskogo gosudarstvennogo universiteta tehnologii $i$ dizajna. Serija 1: Estestvennye $i$ tehnicheskie nauki, 2019, No 2, pp. 79-82.

3. Linnikov O.D., Rodina I.V., Baklanova I.V., Suncov A.Ju., Sorbtsionnye $i$ khromatograficheskie protsessy, 2018, Vol. 18, No 4, pp. 554-562.

4. Abramova A.Ju., Jurchenko V.V., Khimija. Ekologija. Urbanistika, 2018, Vol. 1, pp. 185-188.

5. Linnikov O.D., Rodina I.V., Suncov A.Ju., Sorbtsionnye i khromatograficheskie protsessy, 2017, Vol. 17, No 5, pp. 725-732.

6. Filatova E.G., Pomazkina O.I., Pozhidaev Ju.N., Fizikokhimija poverhnosti $i$ zashhita materialov, 2017, Vol. 53, No 6, pp. 596-601.

7. Jur'eva A.V., Butova T.S., Dinamika sistem, mehanizmov i mashin, 2014, No 3, pp. 318320.

8. Maksatova A.M., Vezencev A.I., Mihajljukova M.O., Kalashnikova L.A., Vestnik sovremennyh issledovanij, 2017, No 7-1 (10), pp. 162-169.

9. Sviridov A.V., Jurchenko V.V., Sviridov V.V., Ganebnyh E.V., Sorbtsionnye i khromatograficheskie protsessy, 2016, Vol. 16., No 1, pp. 78-86.

10. Linnikov O.D., Rodina I.V., Tjutjunnik A.P., Eselevich D.A. et al., Voda: himija $i$ Ekologija. 2016, No 7 (97), pp. 72-80.

11. Harljamov D.A., Nasyrov I.A., Mavrin G.V., Shaikhiev I.G., Vestnik Tehnologicheskogo universiteta, 2015, Vol. 18, No 12, pp. 204-206.
12. Miljutina A.D., Kolesnikov V.A., Uspehi $v$ himii $i$ himicheskoj tehnologii, 2015, Vol. 29, No 1 (160), pp. 43-45.

13. Tsvetkova A.D., Akaev O.P., Vestnik Kostromskogo gosudarstvennogo universiteta im. N.A. Nekrasova, 2011, Vol. 17, No 2, pp. 27-30.

14. Akhrimenko V.E., Akhrimenko Z.M., Sidorova I.I., Poterjaev A.V., Nauka Kubani, 2009, No 4, pp. 20-23.

15. Pimneva L.A., Lebedeva A.A., Mezhdunarodnyj zhurnal jeksperimental'nogo obrazovanija, 2016, No 9-1, pp. 69-70.

16. Miljutina A.D., Kolesnikov V.A., Kolesnikov A.V., Uspehi v himii $i$ himicheskoj tehnologii, 2016, Vol. 30, No 1 (170), pp. 4243.

17. Denisova T.R., Sokolov M.P., Galimova R.Z., Shaikhiev I.G., International Journal of Green Pharmacy, 2017, Vol. 11, No 4, pp. S872-S876.

18. Denisova T.R., Mavrin G.V., Galimova R.Z., Shaikhiev I.G., Research Journal of Pharmaceutical, Biological and Chemical Sciences, 2016, Vol. 7, No 5, pp. 1765-1771.

19. Miftahova F.R., Nguen T.K.T., Galimova R.Z., Shaikhiev I.G., Vestnik Tehnologicheskogo universiteta, 2019, Vol. 22, No 2, pp. 37-43.

20. Miftahova F.R., Nguen T.K.T., Galimova R.Z., Shaikhiev I.G. et al., Sorbtsionnye i khromatograficheskie protsessy, 2019, Vol. 19, No 5, pp. 588-595.

21. Galimova R.Z., Nguen T.K.T., Shaikhiev I.G., Sverguzova S.V., Chemical Bulletin, 2019, Vol. 2, No 4, pp. 12-23.

22. Ugrozov V.V., Filippov A.N., Sidorenko Ju.I., Zhurnal fizicheskoj himii, 2007, Vol. 81, No 3, pp. 458-461. 
23. Nguyen T.K.T., Galimova R.Z., Shaikhiev I.G., Denisova T.R. et al., International Journal of Green Pharmacy, 2018, Vol. 12, No 4, pp. S895-S899.

24. Nguyen T.K.T., Sidorovnina O.O., Zamalieva L.A., Miftahova F.R. et al., Vestnik Tehnologicheskogo universiteta, 2017, Vol. 20, No 18. pp. 159-162.

25. Dagaeva E.V., Valinurova Je.R., Vestnik Bashkirskogo universiteta, 2019, Vol. 24, No 1, pp. 71-75.

26. Nikiforova T.E., Kozlov V.A., Rodionova M.V., Modina E.A., Izvestija vysshih uchebnyh zavedenij. Serija: Himija $i$ himicheskaja tehnologija, 2009, Vol. 52, No 3, pp. 2731.

27. Bagrovskaja N.A., Nikiforova T.E., Kozlov V.A., Lilin S.A., Himija $v$ interesah ustojchivogo razvitija, 2006, Vol. 14, No 1, pp. 1-7.

28. Nikiforova T.E., Bagrovskaja N.A., Kozlov V.A., Lilin S.A., Himija rastitel'nogo syr'ja, 2009, No 1, pp. 5-14.

29. Bagrovskaya N.A., Nikiforova T.E., Kozlov V.A., Russian Journal of Physical Chemistry A, 1999, Vol. 73, No 8, pp. 1305-1309.

30. Kamalova N.A., Shaikhiev I.G., Sadykova S.V., Galimova R.Z., "Innovacionnye podhody $\mathrm{v}$ reshenii sovremennyh problem racional'nogo ispol'zovanija prirodnyh resursov i ohrany okruzhajushhej sredy", sbornik dokladov Mezhdunarodnoj nauchno-tehnicheskoj konferencii, 2019, pp. 196-201.

Галимова Румия Захидовна - доцент кафедры инженерной экологии, канд. техн. наук, Казанский национальный исследовательский технологический университет, Казань

Шайхиев Ильдар Гильманович - заведующий кафедрой инженерной экологии, д-р техн. наук, доцент, Казанский национальный исследовательский технологический университет, Казань

Камалова Надежда Александровна - магистрант кафедры инженерной экологии, Казанский национальный исследовательский технологический университет, Казань

Свергузова Светлана Васильевна - заведующая кафедрой промышленной экологии, дp техн. наук, проф., Белгородский государственный технологический университет им. В.Г. Шухова, Белгород
31. Denisova T.R., Kharlyamov D.A., Galimova R.Z., Shaikhiev I.G. et al., International Journal of Engineering and Technology (UAE), 2018, Vol. 7, No 4.7, pp. 219-222.

32. Kamalova N.A., Galimova R.Z., Shaikhiev I.G., Sadykova S.V. et al., Vestnik Tehnologicheskogo universiteta, 2017, Vol. 20, No 19, pp. 121-124.

33. Kamalova N.A., Shajhiev I.G., Sadykova S.V., "Aktual'nye voprosy ohrany okruzhajushhej sredy", sbornik dokladov Vserossijskoj nauchno-tehnicheskoj konferencii, 2018, pp. 114-118.

34. Kamalova N.A., Shaikhiev I.G., Sadykova S.V, "Innovacionnye puti reshenija aktual'nyh problem prirodopol'zovanija i zashhity okruzhajushhej sredy", sbornik dokladov Mezhdunarodnoj nauchno-tehnicheskoj konferencii, 2018, pp. 113-120.

35. Galimova R.Z., Shaikhiev I.G., Ochistka fenolsoderzhashhih stochnyh vod nativnymi i modificirovannymi adsorbcionnymi materialami na osnove othodov sel'skohozjajstvennogo i promyshlennogo proizvodstva. BelgorodKazan', 2018, 96 p.

36. Galimova R.Z., Shaikhiev I.G., "Innovacionnye podhody $\mathrm{v}$ reshenii sovremennyh problem racional'nogo ispol'zovanija prirodnyh resursov i ohrany okruzhajushhej sredy", sbornik dokladov Mezhdunarodnoj nauchnotehnicheskoj konferencii, 2019, pp. 160-166.

Galimova Rumiya Z. - Assistant of the Department of Environmental Engineering, Ph.D. tech. Sciences, Kazan National Research Technological University, Kazan.

Shaikhiev Ildar G. - Head of the Department of Environmental Engineering, Dr. Tech. Sciences, Associate Professor, Kazan National Research Technological University, Kazan

Kamalova Nadezhda A. - Undergraduate, Department of Environmental Engineering, Kazan National Research Technological University, Kazan

Sverguzova Svetlana V. - Head of the Department of Industrial Ecology, Dr. Tech. Sciences, Professor, Belgorod State Technological University. V.G. Shukhov, Belgorod. 